\title{
Politicisation of performance appraisals
}

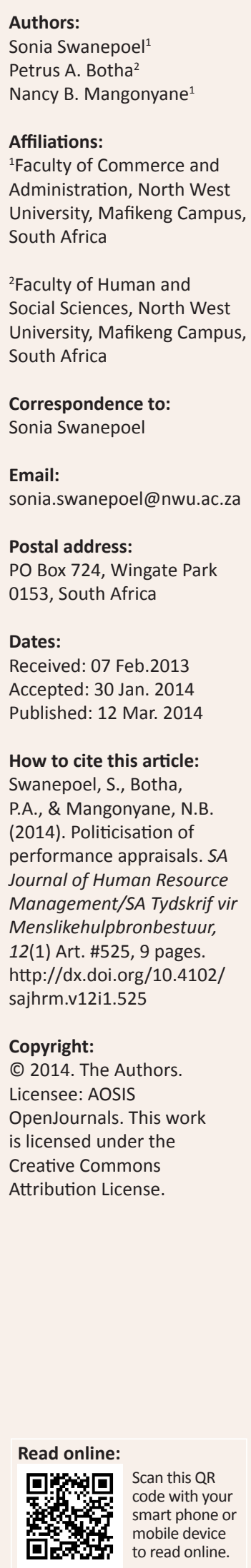

Orientation: Employees are a source of competitive advantage for organisations and human resource management seek to promote employee efficiency. One of the tools organisations utilise to achieve this goal is performance appraisals.

Research purpose: The purpose of this study was to investigate the weaknesses in performance appraisal and to determine whether it is politicised in the North West Department of Health and Social Development in South Africa.

Motivation for study: Many organisations either ignore the existence of politics in the appraisal process or assume that its impact can be minimised if they refine their appraisal instruments. Executives admit that, in appraising others, they often intentionally avoid meeting the goal of accuracy in favour of achieving goals that have more to do with exercising discretion and maintaining departmental effectiveness. Ironically, these same executives lament that the appraisals they receive often do not accurately represent their abilities and performance (Gioia \& Longenecker, 1994).

Research approach, design and method: Self-administered questionnaires were used as a means of collecting data and analysis was done through the use of the Statistical Package for the Social Sciences (SPSS).

Main findings: The results of the study showed that respondents believe that performance appraisals are highly politicised.

Practical/managerial implications: If used effectively, performance appraisals may improve employee productivity and efficiency as well as motivation and performance. However, if performance appraisal is perceived as unfair and political, it can diminish rather than enhance employee attitudes and performance.

Contribution: Amongst others, it is recommended that managers should consider separating assessment for development and assessment for rewards.

\section{Introduction \\ Key focus of the study}

Many organisations are aware of the role employees can play as a source of competitive advantage. As a consequence, organisations implement human resource management (HRM) policies and practices that seek to promote employee productivity and efficiency (Brown \& Benson, 2005; Linna et al., 2012). One of these practices is performance appraisal (PA). If used effectively, PAs may improve employee productivity and efficiency as well as motivation and performance.

\section{Background}

The notion that people at work should be assessed is eminently sensible. This procedure is potentially of enormous benefit to both the individual and the organisation in that the feedback provides people a basis to set goals to both evaluate and improve their performance. Why then are both the provider and recipient of this service frequently dissatisfied with the outcome (Latham, 2008; Shrivastava \& Purang, 2011; Spence \& Keeping, 2011)?

Organisational politics is simply a fact of life. (Gioia \& Longenecker, 1994). For years, personal experiences, hunches and anecdotal evidence have supported a general belief that behaviour in and of organisations is often political in nature. But it is fair to say that there has been a considerable lack of convergence amongst organisational scientists concerning exactly what constitutes political behaviour. Some have defined organisational politics in terms of the behaviour of interest groups to use power to influence decision-making. Others have focused on the selfserving and organisationally non-sanctioned nature of individual behaviour in organisations. Others have characterised organisational politics as a social influence process with potentially 
functional or dysfunctional organisational consequences or simply the management of influence. Perhaps it is these fragmentations and the differing perspectives that have prompted some scholars to state that the meaning of organisational politics remains largely unknown, in spite of the importance of political behaviour to organisational functioning' (Vredenburgh \& Maurer, 1984, p. 47; see also Gandz \& Murray, 1980; Mayes \& Allen, 1977; Shrivastava \& Purang, 2011).

However, if PAs are perceived as unfair, they can diminish rather than enhance employee attitudes and performance. Specifically, perceptions of procedural unfairness in effecting PA can adversely affect employees' organisational commitment, job satisfaction, trust in management and performance, as well as their work-related stress, organisational citizenship behaviour, theft and inclination to litigate against their employer (Colquitt, Conlon, Wesson, Porter \& Ng, 2001; Fanga \& Gerhart, 2012; Greenberg, 1991; Judge \& Colquitt, 2004; Kay, Meyer \& French, 1965; Werner \& Bolino, 1997, cited by Heslin \& Vande Walle, 2009).

If employees believe that the appraisal was undertaken lightly or haphazardly, they may take the process less seriously than they should. Possible legal ramifications exist whenever management is not consistent in its PA procedures. A loss of morale or employee productivity may also result from poorly administered PAs (Grobler, Warnich, Carrell, Elbert \& Hatfield, 2006; Migiro \& Tadera, 2011). It is a well-known axiom that politics often plays a dominant role in important organisational decisions and actions. Although politics is associated with many events in organisational life, the political nature of these events is either too elusive or too cleverly concealed to be discerned easily (Gioia \& Longenecker, 1994).

Many organisations either ignore the existence of politics in the appraisal process or assume that its impact can be minimised if they refine their appraisal instruments. Executives admit that, in appraising others, they often intentionally avoid meeting the goal of accuracy in favour of achieving goals that have more to do with exercising discretion and maintaining departmental effectiveness, that is, they view the appraisal process as a way of achieving desired results, and this priority supersedes their concern for accuracy or playing by the rules. Ironically, these same executives lament that the appraisals they receive often do not accurately represent their abilities and performance (Gioia \& Longenecker, 1994).

In the North West Department of Health and Social Development (NWDoH \& Soc Dev), all managers are expected to have a formal performance review with their employees at least twice a year, and a formal performance feedback session once every quarter (North West Department of Health, 2003). The manager's fundamental responsibility is to get results through people; a systematic approach to assessing the human asset at one's disposal is a must.

\section{Research purpose}

The idea that executives might deliberately distort and manipulate appraisals for political purposes seems unspeakable. Yet there is extensive evidence to indicate that, behind a mask of objectivity and rationality, executives engage in such manipulation in an intentional and systematic manner (Byrne, Pitts, Wilson \& Steiner, 2012; Erdogan, 2002; Ferris, Fedor, Chachere \& Pondy, 1989; Kim \& Rubianty, 2011; Longenecker, Sims \& Gioia, 1992; Salimäki \& Jämsén, 2010; Shrivastava \& Purang, 2011; Spence \& Keeping, 2011).

The purpose of this study was to investigate the weaknesses in performance appraisal and to determine whether it is politicised in the North West Department of Health and Social Development in South Africa.

\section{Literature review \\ Performance appraisal}

Performance appraisal (PA) is a formal, structured system for measuring, evaluating and influencing an employee's job-related attributes, behaviours and outcomes. Its focus is on discovering how productive the employee is and whether they can perform as effectively or more effectively in the future (Haines \& St-Onge, 2012; Hellriegel, Jackson \& Slocum, 2002; Hellriegel, Spence \& Keeping, 2011).

Longenecker, Sims and Gioia (1987) report that:

Almost every executive has dreaded performance appraisal at some time or the other. They hate to give them and they hate to receive them. Yet like them or not, every executive recognises that appraisals are a fact of organisational life.

Certain organisational processes lend themselves to being viewed as more political than others. They are processes in which managerial discretion is high and which relate to success or failure at work, relationships with superiors and inter-unit lateral relations. Insofar as an individual, or others positively regarded, may not succeed to the level expected, it is convenient to believe the decisions were not rational and hence were political (Haines \& St-Onge, 2012; Kim \& Rubianty, 2011; Shrivastava \& Purang, 2011). To the extent that processes such as work appraisals, promotions or transfers rest in fact on ill-defined, poorly known or ambiguous criteria, such perceptions will be exacerbated (Gandz \& Murray, 1980).

The purpose and objective of performance appraisals: The overall purpose of appraisal is to provide information about work performance. (Macan et al., 2011; Swanepoel, Erasmus, Van Wyk \& Schenk, 2003). Jawahaar (2006) sees the purpose of formal PAs as the provision of clear, performance-based feedback to employees.

Performance should be limited to the evaluation of employee goal attainment, employee compliance with the shared values of the organisation and the extent to which managers, supervisors and employees live these values. In the case of supervisors and managers, it is also important to measure 
the extent to which they unlock and utilise the potential of their team members. This implies that the performance of managers and supervisors should also be measured in terms of their core task - the extent to which they have succeeded in making their team members successful (Coetsee, 2002).

W. Edwards Demming, known as the leading personality of the quality revolution, labelled performance appraisal systems a 'deadly disease' in organisations, and claimed that they 'leave people bitter, crushed, bruised, battered, desolate, despondent, dejected, feeling inferior, some even depressed, unfit for work for weeks after receipt of rating, unable to comprehend why they are inferior and both appraisers and appraisees alike find the PA process unpleasant' (cited in Scullen, 2011, p. 8).

Key challenges of performance appraisals: There are probably as many problems associated with PA as there are reasons for its existence. At the centre of the organisational performance challenge lies the need to objectively define measurable performance criteria and then to effectively attract, select, develop and reward or retain competence (Charlton, 2000). A major problem of PA is the dichotomy between quantity and the quality of work. Too often a blanket approach is utilised to evaluate employees on the quantity of work performed and not necessarily on its quality. It is relatively easy to record the quantity of work performed but not so easy to estimate the quality of the same or other work (Hoskins, Leach \& Neerputh, 2006).

Other weaknesses according to Analoui (2007) are that too often jobs have vague and unclear performance standards; as such the employees have to guess what is expected of them. Worse still, the performance standards are often set in isolation from employees, and this creates alienation and a lack of identification on their part. It is vital therefore to create a two-way channel of information between the managers and the employees regarding performance standards and expectations.

Research on performance measurement in the public sector, which is generally a provider of services, indicates several difficulties such as the defining of outputs, vagueness of performance dimensions and that lines of accountability are complex (Smith, 1990; Van der Waldt, 2004).

Government and politicisation: In the discussion of performance management development system in the North West Department of Health and Social Development (NWDoH \& Soc Dev), the focus is on issues impacting on the appraisal of the performance of programme managers, middle managers as well as junior staff members on levels $3-12$, and the effect that the method or system has on the outcome with a view to developing acceptable guidelines or management for such appraisal. Poole and Warner (1998, cited by Neerputh, Leach \& Hoskins, 2006, p. 53) state that 'the issue is not whether performance should be measured, but how?'
Transformation and reform: The government regards transformation as a dynamic, focused and relatively shortterm process, designed to fundamentally reshape the public service for its appointed role in the new dispensation in South Africa. (Republic of South Africa, 1995).

Rationale for performance management: The government's vision, mission and priorities can only find meaning provided its executive arm carries its mandate to the public in an efficient and effective manner. The development of a new organisational culture is critical to the improvement of efficient and effective public service delivery. These changes needed to be accompanied by a major shift from a rule-bound culture to one that is focused more on the achievement of objectives and the meeting of needs (North West Provincial Government, 1997).

The meaning of politicisation: There is lack of uniformity in the ways in which different writers define politicisation, commonly known as organisational or workplace politics. In one category are those who define it in a 'neutral' fashion as the occurrence of certain forms of behaviour associated with the use of power or influence. A second group tends to define it in terms of an actor's subjectively realised intention of engaging in self-serving behaviours at the expense of others in the organisation (Gandz \& Murray, 1980).

According to Gioia \& Longenecker (1994), many organisations either ignore the existence of politics in the appraisal process or assume that its impact can be minimised if they refine their appraisal instruments. For good or bad reasons, supervisors and managers make advance decisions of what they want to see happen and then use ratings as a vehicle to get those results. The goal may be to get someone a hefty pay raise or to ensure that someone is barred from promotion and this results in politicisation (Coens \& Jenkins, 2000).

It is important for organisations to note that:

politics in employee appraisal will never be entirely squelched. More candidly, there is some place for politics in the appraisal process to facilitate necessary executive discretion. The goal then, is not to arbitrarily and ruthlessly try to eliminate politics but, instead, to effectively manage the role politics plays in employee appraisal (Longenecker et al., 1987, p. 191).

The focus of this research is on the second definition and the fact that organisations politicise performance appraisals and that this devalues the essence of appraising (Tziner, Latham, Price \& Haccoun, 1996). Weller (1989, cited by Mulgan, 1998) begins with the assumption that politicisation is to be seen as the opposite of political neutrality. He then identifies it with two tendencies which can be said to contradict two aspects of neutrality: the use of the public service for party purposes and the appointment, promotion and tenure of public servants through party political influences.

The nature of politics in executive appraisal: At the heart of many appraisal function is an assessment and an evaluation of performance. The goal is fair and 'objective' measurement 
- measurement of the quality of one's work and how it stands up against some standard or in comparison to others. It is known that the raters do not have all the facts, that appraisal is not particularly reliable, but they nonetheless pretend that it is a valid measurement as Gioia and Longenecker (1994, p. 50) further mention that:

- Politics is prevalent in appraisal, and the higher one rises in the [organisation], the more political the appraisal process becomes.

- Appraisals are susceptible to political manipulation because of the dynamic, ambiguous nature of managerial work. Any rating a manager receives can be justified in some way, even if it is inaccurate.

- Performance is not necessarily the bottom line in the executive appraisal process. It is easy to be kept in the dark if you don't know what counts, so you become apprehensive and suspicious that you are being used for someone else's ends.'

- Senior executives have extraordinary latitude in evaluating subordinate executives' performance.

- Executive appraisal is a political tool used to control people and resources.

Consequences of corrupt executive appraisal: The manipulative practices in executive appraisals unquestionably undermine the designed purpose of executive review, sacrificing fairness and benefiting some people at the expense of others. In addition to producing consequences and costs for individuals, these practices almost always hurt the organisation as a whole because of the following reasons:

- Political appraisals undermine [organisational] goals and performance.

- Political appraisals compromise the link between executive performance and outcomes. Most junior executives avoid clashing with their boss, because the confrontation amounts to an unequal power contest they cannot possibly win. As a consequence, ambiguities persist and the junior executive's performance suffers.

- Appraisal politics inhibits executive development. When appraisals are inflated for political reasons, they give the junior executive a false sense of security, and often undesired behaviours; when ratings are intentionally deflated, frustration, self-doubt, bitterness, and withdrawal can result.

- Politics at the executive level begets politics in the rest of the organisation. If the top of the organisation is characterised by politically driven promotions, bonuses and rewards, similar practices are sure to occur at lower levels. The net effect is blanket cynicism and suspicion about the appraisal process itself. The political appraisal thus becomes a triggering event, with politics eventually showing up in other organisational domains (Gioia and Longenecker, 1994, p. 55).

- Political appraisals can expose an organisation to litigation when executives are terminated. Without some assessment, an organisation cannot weed out unacceptable probationary employees. Without some evaluative information, it may be difficult for some employees to identify strengths to build from or weaknesses to work on. Without assessment, we cannot choose the best candidates for promotion, nor can we identify those who are bad fits and should be encouraged to pursue new career paths (Coens \& Jenkins, 2000).

Political problems: Whilst rating errors and bias may be subconscious and unintended, research demonstrates that both the rater and the ratee deliberately distort, abuse or misuse the process with political motives. According to Rusli Ahmad (2007, cited by Ahmad \& Lemba, 2010), PA involves the use of various types of political influences and power and the relationship between employee and manager or superordinates and subordinates or raters and ratees will build an internal political relationship. In fact, it is not an exaggeration to say that the first rule of corporate politics is that there are no rules.

Managerial politics: For good or bad reasons, supervisors and managers make advance decisions of what they want to see happen and then use ratings as a vehicle to get those results. The goal may be to get someone a hefty pay raise or to ensure that someone is barred from promotion. As supervisors compress PAs for motivational purposes, this political behaviour might be perceived to represent managerial discretion exercised to ensure the attainment of goals and potentially benefit the individual employee and even the organisation as a whole. As a result, it might be perceived an effective use of the pay system (Salimäki \& Jamsen, 2010).

Political abuse by employees: Employees too, attempt to manoeuvre and distort the system. Researchers call this impression management, which comes in many variations more commonly known as 'brown-nosing' or 'hey-lookwhat-I-did'. Employees know when appraisal time is coming around - they start saying good morning and take time to chitchat with the boss. Whilst obvious or aggressive impression management may backfire, some research indicates that managers give the highest raises to politically connected people who would threaten to complain if they did not get a substantial pay raise (Coens \& Jenkins, 2000).

International versus local perspective: According to Grobler et al. (2006) PA is not only implemented in local organisations but throughout the whole world, in public and private organisations. Going global will inevitably impact on the activities performed by the company's HR department. The PA process helps to clarify performance expectations, provide a framework for progress reviews and identify developmental needs. It would be correct to conclude that for most employees, PA is an inherently natural management practice - even when it is not well done. This conclusion may not hold for the manager working in Latin America, the Middle East or any number of non-Western countries. A variation of the critical incidents method is used for employees in Chinese companies, but in none of these is the PA used as evidence for promotion and merit pay decisions. Seniority (time on the job) is considered the most important determinant when it comes to these decisions. 
When evaluating employees of the host country, the process can be extremely frustrating to someone who is not familiar with the local culture's expectation of the roles of the boss and the subordinate. Different cultures have their own ideas and beliefs about what the culture defines as incompetent, mediocre and excellent work performance. In most countries, it is performance that counts; in Islamic countries, however, it may be the subordinate's personality and social behaviour not job performance - that matter. Besides the cultural issues that complicate PA in the international environment, there are many other issues that also make it extremely difficult. Although these issues can complicate the PA process, it is important that some type of evaluation takes place as it has a major impact on the expatriate's promotion and career alternatives upon repatriation back home (Grobler et al., 2006).

In supporting the need for human capital development, the Malaysian government implemented the HR Development Act in 1992 to assist unskilled and skilled workers to achieve an adequate level of the skills and knowledge required to perform effectively in organisations. It was under this legislation that government implemented numerous incentives to assist employers in the manufacturing industries to develop its employees. Kirkpatrick (1996, cited by Abdullah, Ahsan \& Alam, 2009) indicates that in evaluating employees' learning, the organisation will be looking for evidence of how changed job behaviour influences other employees and the way the organisation functions. This would mean measuring changes in overall organisational functioning with respect to productivity, output and costs, but such an exercise would be difficult to undertake.

South Africa's performance appraisal dilemma: According to Grobler et al. (2006), a comprehensive survey of nine leading South African organisations undertaken by the University of Stellenbosch Business School revealed a rather bleak picture of the way employee performance is managed and rewarded in SA. Major problems that were identified during the survey include the existence of a rather negative working culture, changes in corporate strategy that did not result in corresponding behaviour changes and insufficient line management support for performance management. Regarding periodic and formal reviews, it became apparent that there was: a lack of follow-up of performance reviews, over-emphasis on the appraisal aspect at the expense of development, inadequate performance information and inadequately maintained objectivity.

\section{Research design \\ Method \\ Research participants}

In this research, the population figure of 300 was obtained from the Persal system at the time the research was done and comprises the total number of employees at levels 3-12 of the filled posts at head office. Levels 9-12 are managers, levels 7-8 supervisors, whilst non-managerial roles are levels 6 and below.
The study used simple random sampling to arrive at the group of employees chosen to participate. Since there were 300 employees on levels 3-12 who were targeted for the study, 150 employees were randomly selected, thus $50 \%$ of the population; 108 employees responded $(73 \%$ response rate). Amongst the respondents $60(56 \%)$ are female whilst 48 (44\%) are male. Babbie and Mouton (2001) indicate that a response rate of $50 \%$ is adequate for analysis, whilst response rates of $60 \%$ and $70 \%$ are good and very good, respectively. The questionnaire response rate obtained in the study was therefore considered to be sufficient for analysis.

The majority of respondents (34.7\%) are in non-managerial positions, whilst $33.7 \%$ are supervisors and the minority of respondents $(31.6 \%)$ are in management positions. Most of the respondents, $51.0 \%$, have either a diploma or a degree qualification and $23.0 \%$ hold an honours or master's degree.

\section{Measuring instruments}

The first part of the questionnaire (section A, questions 1-11), which focused on the demographics, was taken from Louw (2006); some alterations were made: the current salary level was included and the educational qualifications were extended to include honours degree, master's degree and higher. The second part (section B, a pre-coded questionnaire numbered 1-25), was taken from Tziner et al. (1996) and is considered to be one of the standard questionnaires on politicisation. It consisted mainly of open-ended questions and was utilised with minor alterations. The questionnaire was pre-tested on 10 employees of the NWDoH in Mahikeng and their contributions were incorporated.

\section{Research procedure}

Self-administered questionnaires were utilised to collect data. Each questionnaire included a covering letter inviting subjects to participate in the study voluntarily. It assured them that their responses would remain confidential. The covering letter stated that completing the questionnaires and returning them meant that the participants agreed that the researcher could use the results for research purposes only. One hundred and fifty (150) questionnaires were distributed to participants and a further 50 questionnaires were emailed to participants. Participants were requested to complete the questionnaire within 10 days.

It is believed that the population from which the sample was drawn was representative of the public service. The reason for this is that, firstly, experience has shown that the specific comments or criticisms concerning PA are common throughout the public service. Secondly, with the constant migration of public servants through inter-departmental and inter-provincial transfers, it can be expected that the application of the system must become more and more stereotyped and therefore be subject to similar criticisms throughout the public service. Thirdly, because the system is universally applicable throughout the public service, training methods and information concerning the administration of the system are originated and controlled from a single 
central source. This means that individual departments cannot deviate from the rules as set out in the Public Service staff code, leading to a situation which also lends itself to uniformity (Rademan \& Vos, 2001).

\section{Statistical analysis}

The statistical analysis was done through the use of the Statistical Package for the Social Sciences (SPSS). Each question of the questionnaire was analysed separately. Descriptive statistics, reliability, validity and correlation statistics were utilised to analyse the data.

\section{Results \\ Reliability}

According to George and Mallery (2006), the closer the Cronbach's alpha is to 1, the greater the internal consistency of items in the instrument being assessed. From the reliability statistics given in Table 1, it is observed that the Cronbach's alpha coefficient is 0.733 for the demographics data and 0.760 for the performance and politicisation data. It is therefore deduced that the research instrument for this study is reliable and the results it produced can be trusted.

\section{Test of significance (Spearman's rank correlation)}

The $p$-values (0.024 and 0.043) in Table 1 are lower than the 0.050 level of significance. This shows that the correlation between educational qualification and perception of employees about performance appraisals is significant. The positive correlation coefficients (0.215 and 0.195) imply that highly qualified employees tend to disagree with the statements listed in Table 1, whereas less qualified employees tend to agree.

The $p$-values in Table 2 are lower than the 0.05 level of significance. This shows that the correlation between work experience and perception of employees about performance appraisals is significant. The negative correlation coefficients $(-0.199,-0.217,-0.248$ and -0.192$)$ imply that more experienced employees tend to agree with the statements listed in Table 2, whereas less experienced employees tend to disagree.

\section{Politicisation of performance appraisals}

Table 3 indicates the percentage of respondents who agree with the statement.

\section{$t$-test between subgroups in samples}

The statistical software package (SPSS 18.0) was used to perform a $t$-test between two independent samples (male and female employees). Since the $p$-value is lower than the 0.05 level of significance, it means that the correlation is significant.

\section{Chi-square test of independence}

This test of independence is concerned with the relationship between two different factors (or categories) in a population under study (see Table 4).

Microsoft Excel was used to perform a chi-square test for the data in Table 4. The chi-square statistic and the $p$-value with one degree of freedom are 3.193 and 0.074, respectively. Since the $p$-value is lower than the $10 \%$ level of significance, the opinion of employees about the performance appraisal procedure in the department is significantly dependent on their gender. It means that the majority $(14 / 23=61 \%)$ of employees who tend to agree that the performance appraisal procedure in the department is fair and transparent are men, whereas the majority $(51 / 85=60 \%)$ of the employees who tend to disagree are women.

\section{Discussion}

This research revealed that there is some form of politicisation in the way in which PAs are conducted in the department. The results show that the correlation between age category and the perception of employees about PA is significant since the $p$-values are less than 0.05 . There is a difference in the perception of younger and older

TABLE 1: Spearman's rank correlation between educational qualification and perception of employees about performance appraisals.

\begin{tabular}{|c|c|c|}
\hline Perception & Correlation coefficient & $\begin{array}{l}\text { Educational } \\
\text { qualification }\end{array}$ \\
\hline \multirow{2}{*}{$\begin{array}{l}\text { Supervisors avoid giving performance appraisals that may have negative consequences for the employees (e.g. no } \\
\text { promotion, layoff, no bonus, salary freezes, etc.). }\end{array}$} & Correlation coefficient $(r)$ & 0.215 \\
\hline & $p$-value & 0.024 \\
\hline \multirow{2}{*}{$\begin{array}{l}\text { Employees holding a high status position in their organisation will get a higher performance appraisal than is } \\
\text { deserved (i.e. regardless of their real performance, employee appraisals are affected by the organisational status } \\
\text { of the positions they hold). }\end{array}$} & Correlation coefficient $(r)$ & 0.195 \\
\hline & $p$-value & 0.043 \\
\hline
\end{tabular}

TABLE 2: Spearman's rank correlation between work experience and perception of employees about performance appraisals.

\begin{tabular}{|c|c|c|}
\hline Perception & Correlation coefficient & Work experience \\
\hline \multirow[t]{2}{*}{ Supervisors avoid giving performance appraisals that may antagonise employees (e.g. a low rating). } & Correlation coefficient $(r)$ & -0.199 \\
\hline & $p$-value & 0.040 \\
\hline \multirow[t]{2}{*}{ Supervisors inflate the performance appraisals of employees who have access to valuable sources of information. } & Correlation coefficient $(r)$ & -0.217 \\
\hline & $p$-value & 0.023 \\
\hline \multirow{2}{*}{$\begin{array}{l}\text { Supervisors are likely to give an inflated performance appraisal in order to avoid negative or uncomfortable } \\
\text { feedback sessions with subordinates. }\end{array}$} & Correlation coefficient $(r)$ & -0.248 \\
\hline & $p$-value & 0.009 \\
\hline \multirow{2}{*}{$\begin{array}{l}\text { Supervisors produce accurate performance appraisals only to the extent that they may be rewarded for doing so or } \\
\text { failing to do so. }\end{array}$} & Correlation coefficient $(r)$ & -0.192 \\
\hline & $p$-value & 0.045 \\
\hline
\end{tabular}


TABLE 3: Response percentages.

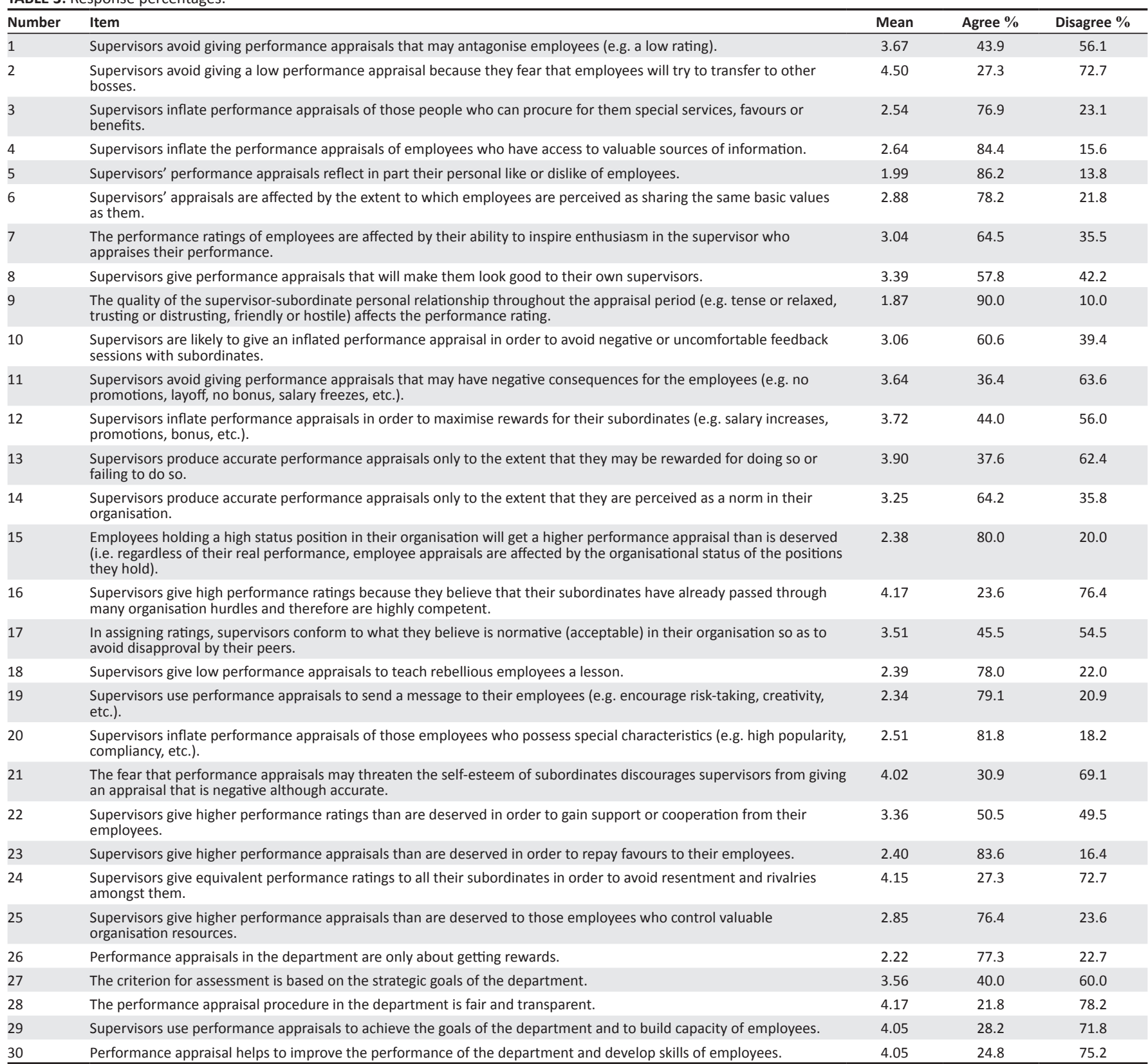

people regarding some aspects of PA. It was found that the correlation between educational qualifications and work experience and PA is also significant. Furthermore, the findings of the Spearman's rank correlation showed that the correlation between the period of conducting PA and age, educational qualifications and work experience is also significant. Employees of 31 years and older, with higher qualifications and more experience, believe that PAs should be conducted more regularly.

\section{Summary of key findings}

The PAs in the North West Department of Health and Social Development have a number of weaknesses, as shown by the responses from the outcome of the research. The following aspects have been identified for discussion as they show a high response rate by respondents.
TABLE 4: Cross-tabulation of employee opinions about performance appraisals by gender.

\begin{tabular}{lccc}
\hline Gender & \multicolumn{3}{c}{$\begin{array}{l}\text { Statement: } \\
\text { procedure in the department is fair and } \\
\text { transparent. }\end{array}$} \\
\cline { 2 - 4 } & Agree & Disagree & Total \\
\hline Female & 9 & 51 & 60 \\
Male & 14 & 34 & 48 \\
\hline Total & 23 & 85 & 108 \\
\hline
\end{tabular}

Chi-square $=3.193$

$p$-value $=0.074$

$d f=1$

\section{Forms of favouritism}

Respondents indicated that managers allocate higher performance appraisals than are deserved:

- in order to repay favours to their employees, $82 \%$

- to procure special services, favours or benefits, $73 \%$

- to employees who control valuable organisation resources, $75 \%$ 
- to access information, $82 \%$

- to reward employees they like, $84 \%$

- to employees who share the same values, $78 \%$

- to employees holding a high status position in the organisation, $82 \%$

- to employees who have certain characteristics (e.g. high popularity, compliancy, etc.), $81 \%$.

Coetsee (2002) is of the view that one of the most common deficiencies of performance evaluation systems is that unnecessary factors are measured, such as certain irrelevant personality traits. A high number $(78 \%)$ of the respondents agree that supervisors give low performance appraisals to teach rebellious employees a lesson as well as to send a message to their employees. These findings reveal that performance appraisals are not handled properly and fairly in the department. Supervisors use them to settle personal vendettas or differences, which is a serious weakness. The findings further show that some employees are unfairly victimised due to other things than their actual performance through the use of performance appraisals. Performance appraisal should focus on the performance of employees in doing the work that was planned with the supervisor and not be used as a way to discourage risk-taking, creativity and so on. Supervisors should devise other strategies to motivate and mobilise employees to do their work better.

\section{Respondents further indicated that:}

- performance appraisal in the department is only done for reward, $85 \%$

- the quality of the supervisor-subordinate personal relationship affects the performance rating, 92\%

- the criterion for assessment is based on the strategic goals of the department, $60 \%$

- managers inflate performance appraisals in order to maximise rewards for their subordinates (e.g. salary increases, promotions, layoff, no bonus, salary freezes, etc.), $51 \%$

- supervisors use performance appraisals to send a message to their employees, $78 \%$

- employees holding a high status position in the organisation will receive higher PAs than are deserved, 90\%

- $\quad$ PAs are not fair and transparent, $77 \%$.

The above weaknesses are good examples of politicisation in an organisation in which management discretion is high and determines the success or failure of subordinates. This happens to the extent that processes such as work appraisals, promotions and transfers rest on ill-defined, poorly known or ambiguous criteria and so such perceptions are exacerbated (Gandz \& Murray, 1980). It suggests that supervisors use PAs for their own personal gain and not to improve service delivery or to develop and reward employees.

\section{Limitations}

This study has been limited to the department of Health and Social Development, head office only, which could limit the generalisations of the findings. The districts, which form a major part of the department, have not been included.

\section{Conclusions}

It is therefore important that when PAs are held, managers or raters should be aware that PAs are not a 'one size fits all'. Again, jobs differ in content and expected results; thus, it is important that organisations develop different sets of PA that will cover specific task and job holders (Migiro \& Taderera, 2011).

On the issue of inflating results, managers should realise that perceptions of procedural unfairness can adversely affect employees' organisational commitment, job satisfaction, trust in management and performance as well as their workrelated stress, theft and inclination to litigate against the employer (Heslin \& Vande Walle, 2009);

On the issue of PAs being about rewards only, managers should consider separating assessment for development and assessment for rewards. Linkage to rewards outcomes reduces or eliminates the developmental value of appraisals.

To eliminate any problems of bias, discrimination, favouritism or the like, a PA system needs to include a review mechanism. The next higher level of management, usually the evaluator's immediate supervisor, should automatically review all evaluations of employees made by subordinate managers. The purpose of this managerial review is for auditing the evaluation for fairness, consistency and accuracy and assuring that the evaluator has carried out their function objectively (Fanga \& Gerhart, 2012).

Organisations should also have appraisal appeal procedures. An appeal process would serve three purposes: (1) it protects employees from unfair appraisals, (2) it protects the organisation from potential charges of unfairness and (3) it helps to assure that appraisers do a more conscientious job evaluation because they know their appraisals are subject to examination by others in the organisation (Allen \& Rush, 1998; Curath \& Humprey, 2008, cited by Migiro \& Taderera, 2011).

It is vital therefore to create a two-way channel of communication between managers and employees regarding performance standards and expectations, as Analoui (2007) puts it, so that the managers are not accused of politicising appraisals.

The conclusion is thus made that there are weaknesses in the manner in which PAs in the department are conducted. It has also been confirmed that the process is highly politicised as could be seen by the high percentage rates given by respondents.

\section{Acknowledgement Competing interests}

The authors declare that they have no financial or personal relationship(s) that may have inappropriately influenced them in writing this article. 


\section{Authors' contributions}

S.S. (North-West University) was the project leader and wrote the article. P.A.B. (North-West University) assisted with the technical aspects and aspects of the literature review and B.N.M. (North-West University) collected the data.

\section{References}

Abdullah, Z., Ahsan, N., \& Alam, S.S. (2009). The effect of human resource management practices on business performance among private companies in Malaysia. International Journal of Business and Management, 4(6), 65-72.

Ahmad, R., \& Lemba, C. (2010). Performance appraisal politics and employee turnover intention. Jurnal Kemanusiaan, 16, 1-11.

Allen, T.D., \& Rush, M.C. (1998). The effects of organizational citizenship behavio on performance judgments: A field study and a laboratory experiment. Journal of Applied Psychology, 83(2), 247-260. http://dx.doi.org/10.1037/0021 9010.83.2.247

Analoui, F. (2007). Strategic Human Resource Management. London, UK: Thomson Learning.

Babbie, E., \& Mouton, J. (2001). The practice of social research, Cape Town, South Africa: Oxford University Press.

Brown, M., \& Benson, J. (2005). Managing to overload? Work overload and performance appraisal processes. Group and Organisation Management, 30(1) 99-124. http://dx.doi.org/10.1177/1059601104269117

Byrne, Z.S., Pitts, V.E., Wilson, C.M., \& Steiner, Z.J. (2012). Trusting the fair supervisor: The role of supervisory support in performance appraisals, Human Resource Management Journal, 22 (2), 129-147. http://dx.doi.org/10.1111/j.17488583.2012.00193.x

Charlton, G. (2000). Human habits of highly effective organisations: The human race. Pretoria, South Africa: Van Schaik.

Coens, T., \& Jenkins, M. (2000). Abolishing Performance Appraisals. (2nd edn.). Oak Park, CA: Velocity Business Publishing.

Coetsee, L.D. (2002). Peak Performance and productivity: A practical guide for the creation of a motivating climate. Vanderbijlpark, South Africa: Ons Drukkers.

Colquitt, J.A., Conlon, D.E., Wesson, M.J., Porter, C.O., \& Ng, K.Y. (2001). Justice at the millennium: A meta-analytic review of 25 years of organizational justice research. Journal of Applied
9010.86.3.425

Erdogan, B. (2002). Antecedents and consequences of justice perceptions in performance appraisals. Human Resource Management Review, 12(4), 555-578. performance appraisals. Human Resource Manage
$\mathrm{http}: / / \mathrm{dx}$.doi.org/10.1016/S1053-4822(02)00070-0

Fanga, M., \& Gerhart, B. (2012). Does pay for performance diminish intrinsic interest? International Journal of Human Resource Management, 23(6), 1176-1196. http:// dx.doi.org/10.1080/09585192.2011.561227

Ferris, G.R., Russ, G.S., \& Fandt, P.M. (1989). Politics in organisations. In R.A. Giacolone, \& P. Rosenfeld (Eds.), Impression management in the organisation (pp. 143-170). Hillsdale, NJ: Lawrence Erlbaum.

Gandz, J., \& Murray, V.V. (1980). The experience of workplace politics. The Academy of Management Journal, 23(2), 237-251. http://dx.doi.org/10.2307/255429

George, D., \& Mallery, P. (2006). SPSS for windows step by step: A simple guide and reference. (6th edn.). Boston, MA: Pearson Education.

Gioia, D.A., \& Longenecker, C.O. (1994). Delving into the dark side: The politics of executive appraisal. Organisational Dynamics, 22(3), 47-58. http://dx.doi org/10.1016/0090-2616(94)90047-7

Greenberg, J. (1991). Using explanations to manage impressions of performance appraisal fairness. Employee Responsibilities and Rights Journal, 4(1), 51-60. http://dx.doi/ 10.1007/BF01390438

Grobler, P., Warnich, S., Carrell, M.R., Elbert, N.F., \& Hatfield, R.D. (2006). Human Resource management in South Africa. (3rd edn). London, UK: Thomson Learning.

Haines, V.Y. III, \& St-Onge, S. (2012). Performance management effectiveness: Practices or context? The International Journal of Human Resource Management, 23(6), 1158-1175. http://dx.doi.org/10.1080/09585192.2011.561230

Hellriegel D., Jackson, S.E., \& Slocum, J. Jr. (2002). Management: A competency-based approach. (9th edn.). Australia: Thomson Learning, South-Western.

Heslin, P.A. and Vande Walle, D. (2009). Performance appraisal procedural justice: The role of a manager's implicit person theory. Journal of Management, 20(10), 1-25. role of a manager's implicit person theory. Journal of Management,
$\mathrm{http}: / / \mathrm{dx}$.doi.org/http://dx.doi.org/10.1177/0149206309342895

Hoskins, R., Leach, A., \& Neerputh, S. (2006). Towards establishing guidelines for performance appraisal of subject librarians in Kwa-Zulu-Natal academic libraries. Mousaion, 24(1), 51-74.

Judge, T.A., \& Colquitt, J.A. (2004). Organizational justice and stress: The mediating role of work-family conflict. Journal of Applied Psychology, 89(3), 395-404. http:// dx.doi.org/395-10.1037/0021-9010.89.3.395

Kay, E., \& Meyer, H.H. (1965). Effects of threat in a performance appraisal interview. Journal of Applied Psychology, 49(5), 311-317. http://dxdoi.org/10.1037/ h0022522

Kirkpatrick, D. (1996). Great ideas revisited: Revisiting Kirkpatrick's four-level model. Training and Development, 50(1), 54-57.
Kim, S.E., \& Rubianty, D. (2011). Perceived Fairness of performance appraisals in the federal government: Does it matter? Review of Public Personnel Administration, 31(4), 329-348. http://dx.doi.org/10.1177/0734371X11428903

Jawahaar, I.M. (2006). An investigation of potential consequences of satisfaction with appraisal feedback. Journal of Leadership and Organisational Studies, 13(2), 1428. http://dx.doi.org/10.1177/10717919070130020101

Latham, G.P., Budworth, M., Yanar, B., \& Whyte, G. (2008). The influence of a manager's own performance appraisal on the evaluation of others. International Journal of Selection and Assessment, 16(3), 220-228. http://dx.doi.org/10.1111/ j.1468-2389.2008.00428.x

Linna, A, Elovainio, M., Van den Bos, K., Kivimäki, M., Pentti, J., \& Vahtera, J. (2012) Can usefulness of performance appraisal interviews change organizational justice perceptions? A 4-year longitudinal study among public sector employees. The International Journal of Human Resource Management, 23(7), 1360-1375. http:// dx.doi.org/10.1080/09585192.2011.579915

Longenecker, C.O., Sims, H.P., \& Gioia, D.A. (1987). Behind the mask: The politics of employee appraisal. The Academy of Management Executive, 1(3), 183-193. http://dx.doi.org/10.5465/AME.1992.4274393

Longenecker, C.O., Sims, H.P., \& Gioia, D.A. (1992). The executive appraisal paradox. Academy of Management Executive, 6(2), 18-28. http://dx.doi.org/10.5465/ AME.1987.4275731

Louw, H.J. (2006). Integrating management and employee expectations in determining organisation-specific performance appraisal systems' design. Unpublished master's thesis, University of Pretoria, Pretoria, South Africa.

Macan, T., Mehner, K., Havill, L., Meriac, J.P., Roberts, L., \& Heft, L. (2011). Two for the price of one: Assessment center training to focus on behaviors can transfer to performance appraisals. Human Per

Mayes, B.T., \& Allen, R.W. (1977). Toward a definition of organisational politics. Academy of Management Review, 2(4), 672-678.

Migiro, S.O., \& Taderera, M.M. (2011). Evaluating the performance appraisal system in the bank of Botswana. African Journal of Business Management, 5(10), 37653776.

Mulgan, R. (1998). Politicising the Australian public service. Research paper 3. Canberra, Australia: Politics and Public Administration Group.

Neerputh, S., Leach, A., \& Hoskins, R. (2006). Towards establishing guidelines for performance appraisal of subject librarians in Kwazulu-Natal academic libraries. Mousaion, 24(1), 51-74.

North West Provincial Government. (1997). Performance management system. Mmabatho, South Africa: Author.

North West Department of Health. (2003). Policy on performance management and development. Mmabatho, South Africa: Author.

Rademan, D.J., \& Vos, H.D. (2001). Performance appraisals in the public sector: Are they accurate and fair? SA Journal of Industrial Psychology, 27(1), 54-60. http:// dx.doi.org/10.4102/sajip.v27i1.776

Republic of South Africa. (1995). White paper on the transformation of the public service. Pretoria, South Africa: Ministry for the Public Service and Administration.

Salimäki, A., \& Jämsén, S. (2010). Perceptions of politics and fairness in merit pay. Journal of Managerial Psychology, 25(3), 229-251. http://dx.doi. org/10.1108/02683941011023721

Shrivastava, A., \& Purang, P. (2011). Employee perceptions of performance appraisals: A comparative study on Indian banks. The International Journal of Human Resource Management, 22(03), 632-647. http://dx.doi.org/10.1080/09585192. 2011.543639

Scullen, S.E. (2011). Why do you have a performance appraisal system? Drake Management Review, 1(1), 183-193.

Spence, J.R., \& Keeping, L. (2011). Conscious rating distortion in performance appraisal: A review, commentary, and proposed framework for research. Human Resource Management Review, 21(2), 85-95. http://dx.doi.org/10.1016/j. hrmr.2010.09.013

Shrivastava, A., \& Purang, P. (2011). Employee perceptions of performance appraisals: A comparative study on Indian banks. The International Journal of Human Resource Management, 22(3), 632-647. http://dx.doi.org/10.1080/09585192.2 Resource

Smith, P. (1990). The use of performance indicators in the public sector. Journal of the Royal Statistical Society, 153(2), 53-72. http://dx.doi.org/10.2307/2983096

Spence, J.R., \& Keeping, L. (2011). Conscious rating distortion in performance appraisal: A review, commentary, and proposed framework for research. Human Resource Management Review, 21, 85-95. http://dx.doi.org/10.1016/j.hrmr.2010.09.013

Swanepoel, B., Erasmus, B., Van Wyk, M., \& Schenk, H. (2003). South African Human Resource Management: Theory and Practice. (3rd edn.). Epping, Cape Town, South Africa: Formeset.

Tziner, A., Latham, G.P., Price, B.S., \& Haccoun, R. (1996). Development and validation of a questionnaire for measuring perceived political considerations in performance appraisal. Journal of Organisational Behaviour, 17(2), 179-190. http://dx.doi. org/10.1002/(SICI)1099-1379(199603)17:2<179::AID-JOB740>3.0.CO;2-Z

Van der Waldt, G. (2004). Managing performance in the public sector: Concepts, considerations and challenges. Lansdowne, South Africa: Juta \& Co. Ltd.

Vredenburgh, D.J., \& Maurer, J.G. (1984). A process framework of organizational politics. Academy of Management Proceedings, August, 171-175. http://dx.doi. org/10.5465/AMBPP.1981.4976745 